\title{
Fuzzy logic applications for data acquisition systems of practical measurement
}

\author{
Muhamad Haddin, Arief Marwanto, Agus Suprajitno, Munaf Ismail \\ Department of Electrical Engineering, Universitas Islam Sultan Agung, Indonesia
}

\begin{tabular}{l}
\hline \hline Article Info \\
\hline Article history: \\
Received Aug 10, 2018 \\
Revised Dec 9, 2019 \\
Accepted Jan 11, 2020 \\
\hline
\end{tabular}

Keywords:

Data acquisition system Fuzzy logic

Practical measurement

\begin{abstract}
In laboratory works, the error in measurement, reading the measurring devices, similarity of experimental data and lack of understanding of practicum materials are often found. These will lead to the inacurracy and invalid in data obtanined. As an alternative solution, application of fuzzy logic to the data acquisition system using a web server. This research focuses on the design of data acquisition systems with the target of reducing the error rate in measuring experimental data on the laboratory. Data measurement on laboratory practice module is done by taking the analog data resulted from the measurement. Furthermore, the data are converted into digital data via arduino and stored on the server. To get valid data, the server will process the data by using fuzzy logic method. The valid data are integrated into a web server so that it can be accessed as needed. The results showed that the data acquisition system based on fuzzy logic is able to provide recommendation of measurement result on the lab works based on the degree value of membership and truth value. Fuzzy logic will select the measured data with a maximum error percentage of $5 \%$ and select the measurement result which has minimum error rate.
\end{abstract}

Copyright $\odot 2020$ Institute of Advanced Engineering and Science. All rights reserved.

\section{Corresponding Author:}

Muhamad Haddin,

Department of Electrical Engineering,

Universitas Islam Sultan Agung,

Kaligawe Street Km 4, Semarang, Indonesia.

Email: haddin@unissula.ac.id

\section{INTRODUCTION}

In laboratory works, it is still often found measurement error and error reading of measuring instrument. Measurement error during the laboratory causes the measurement data to be incorrect. Laboratory practice with wrong trial data should be repeated. Furthermore, it is also found similarity of experimental data of laboratory practice participants with each other, which causes the truth of the experimental data doubted. The problem that occurs in the implementation of laboratory works is how the participants are capable to know the results of laboratory measurement, whether it meets standards in the scale of theoretical calculations. If there is a significant difference between the experimental results and the results according to calculations, then the laboratory works participants can repeat or check the experiment series [1-11].

The results of invalid laboratory measurements can be caused by error in recording on paper, error in arranging laboratory module and error in reading measuring instrument [12-14]. This may lead to error in the measurement, errors in reading measuring instrument as well as the circuit. Finally these can result in invalid or inaccurate data. Figure 1 shown the mechanism of laboratory measurements conducted by students. Some deviation measurements could come from human error ability whenever they doing his works during measurement. Moreover, false measurement could happen and they need repeated their works or matched back they results with the references. Therefore, inaccuracy and takes times has leads onto drawbacks of manual system for laboratory measurements. To gain high accuracy of the measurement result and error in reading of measuring instrument or cheating practice measurement data, a data acquisition system (DAS) 
is required. Some studies on DAS have been conducted by previous researchers, among others: data acquisition system using fuzzy logic which is functioned collecting sensor data received from many sources selected and forwarded to Enterprise Service Bus (ESB) $[15,16]$ Another study deals with diagnosing system alarms in anesthesia patients by using fuzzy logic based decision support system (DSS) [17-20]. This current research focuses on fuzzy logic based DAS application to detect the level of laboratory measurement error. This system is able to decrease error percentage of measurement result of laboratory module. The design and making of data acquisition system are done by using fuzzy logic as decision of data selection of experimental result which has minimum mistake.

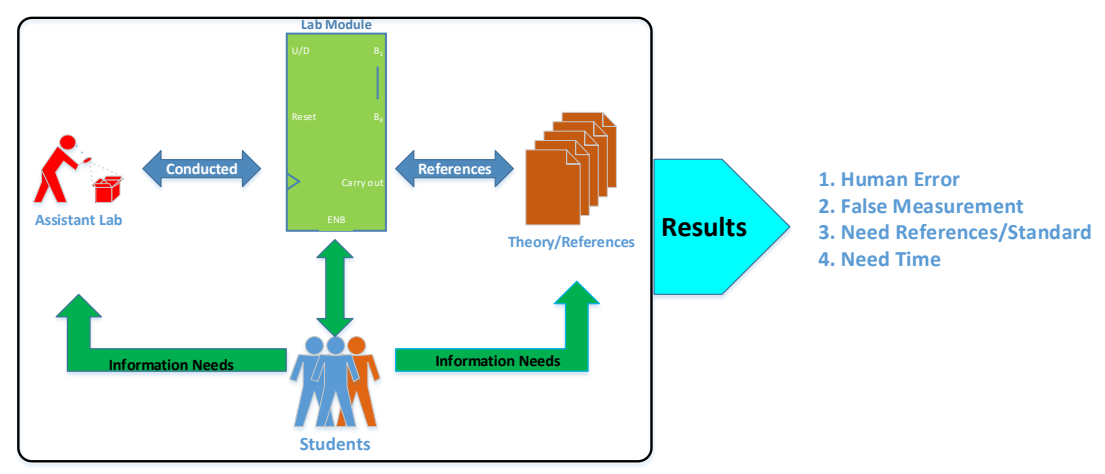

Figure 1. Manually laboratory measurement conduted by students

\section{RESEARCH METHOD}

As shown in Figure 2, the DAS is developed as a tool which is capable to read the practical measurement from analog scale to digital information one. DAS is built using fuzzy logic method that serves to display the level of accuracy and choose the measurement results that have the least percentage of error. So, DAS is able to read the voltage and current measurements and process it by using fuzzy logic method to select the measurement results which have the least level of error. The laboratory work participants can reduce measurement error and store measurement result in web server. The model of this study uses several supporting components as an integrated system. The data acquisition section is a reader of a voltage or current analog signal and converts into a digital signal, then read by Arduino in order to be processed by a computer [21-23]. The physical signal reader is a voltage sensor and ACS712 IC current sensor. Web server application used in this study is XAMPP. The program used in this study is PHP and MySql as data base. The server processes the measurements on practicum module using fuzzy method, resulting in the measurement recommendations used based on the least error rate and the highest degree of fuzzy membership. Fuzzy is one of the best ways to map an input space into an output space. The starting point of the modern concept of uncertainty is that it is introduced about a theory that has objects of a fuzzy set that has imprecise boundaries and membership in a fuzzy set, and not in the form of right or wrong logical, but expressed in degrees [24].

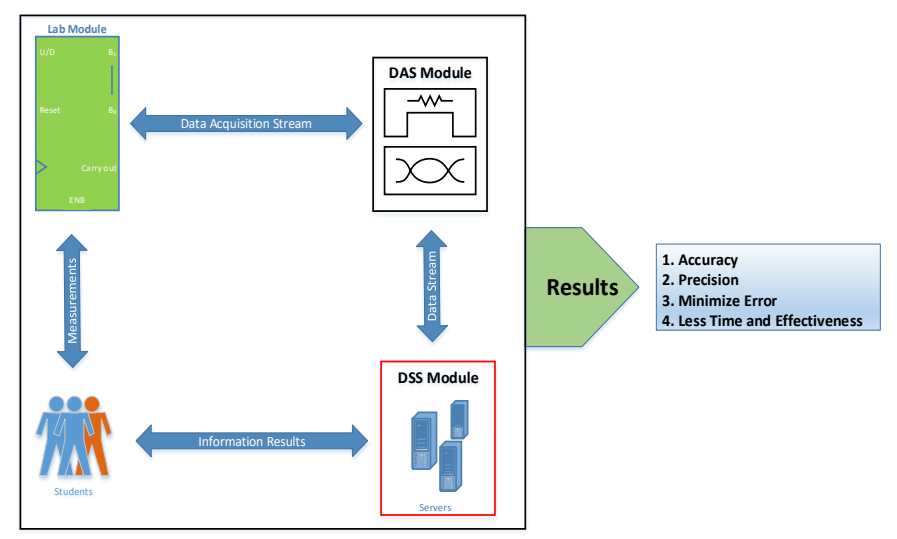

Figure 2. A proposed model of data acquisition system (DAS) based on fuzzy and cloud systems 
In this works, data acquisition systems are proposed whas integrated with decision support system (DSS) and developed in web server application intended to replace laboratory assistant and reference standard value modules. Therefore, the accuracy, the precision, minimizing error and time effectiveness could be achieving and increases the performance knowledge of the students. The function of membership is a curve showing the mapping of data input points into their membership value (also often called as membership degree) which has intervals between 0 and $1[25,26]$.

\subsection{Linear representation}

In a linear representation, the mapping of inputs to the degree of their membership can be described as a straight line. This form is the simplest and the best choice to approach a less obvious concept as shown in Figures 3 and 4.

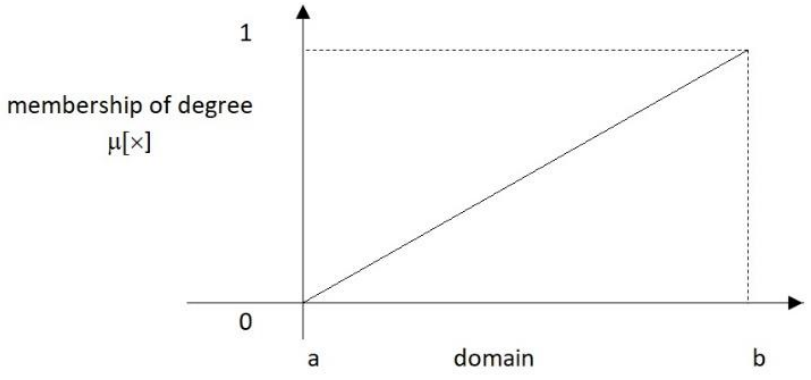

Figure 3. Ascended linear representation

The function of membership is:

$$
\mu[x]=\left\{\begin{array}{lr}
0 ; & x \leq a \\
\frac{x-a}{b-a} ; & a \leq x \leq b \\
1 ; & x \geq b
\end{array}\right.
$$

where $\mathrm{a}, \mathrm{b}$ and $\mathrm{b}$ are the value of domain which has membership degree of 0 , the value of domain which has membership degree of 1 and the value of input which is about to be changed into fuzzy numbers.

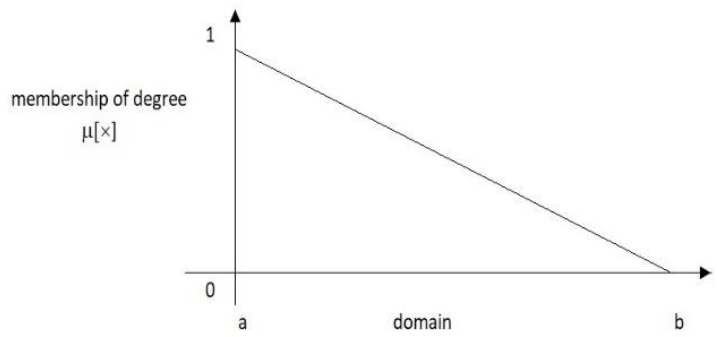

Figure 4. Descended linear representation

The function of membership is:

$$
\mu[x]=\left\{\begin{array}{lr}
0 ; & x \leq a \\
\frac{x-a}{b-a} ; & a \leq x \leq b \\
1 ; & x \geq b
\end{array}\right.
$$

Both descend linear i.e. straight line starts from domain value with the highest member degree on the left side, and then it descends to domain value which has lower member degree. 


\subsection{Triangle curve representation}

The representation of triangle curve is essentially a combination of two linear representations (increase and decrease) as shown in Figure 5.

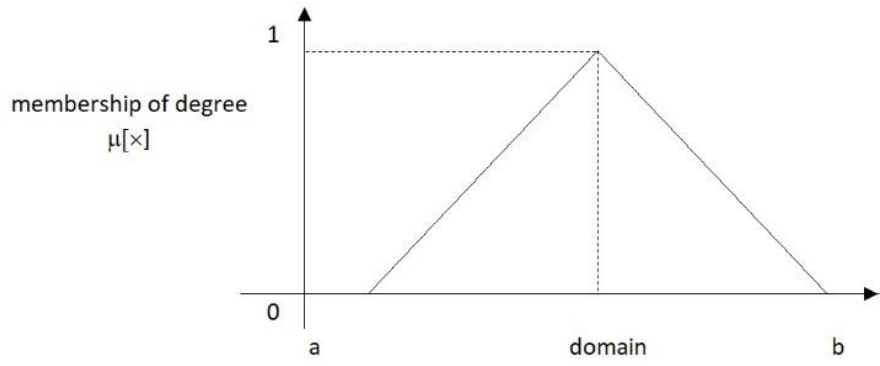

Figure 5. Triangle curve

The function of membership is:

$$
\mu[x]= \begin{cases}0 ; & x \leq a \text { or } x \geq c \\ \frac{(x-a)}{(b-a)} ; & a \leq x \leq b \\ \frac{c-x}{c-b} ; & b \leq x \leq c\end{cases}
$$

where $a, b$ and $c$ are the lowest value of domain which has membership degree of 0 , the value of domain which has membership degree of 1 and the highest value of domain which has membership degree of 0 .

\subsection{Trapezoidal curve representation}

The trapezoid curve is basically a triangular shape, except that there is a point that has a membership value of 1 as shown in Figure 6.

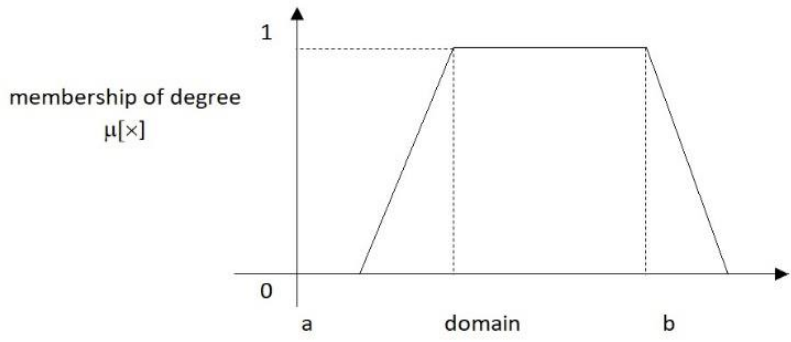

Figure 6. Trapezoidal curve

The function of membership is:

$$
\mu[x, a, b, c, d]=\left\{\begin{array}{lr}
0 ; & x \leq a \\
\frac{(x-a)}{(b-a)} ; & a \leq x \leq b \\
1 ; & b \leq x \leq c \\
\frac{d-x}{d-c} ; & c \leq x \leq d \\
0 ; & x \geq d
\end{array}\right.
$$


where $\mathrm{a}, \mathrm{b}, \mathrm{c}, \mathrm{d}$ and $\mathrm{x}$ are the lowest value of domain which has membership degree of 0 , the lowest value of domain which has membership degree of 1 , the highest value of domain which has membership degree of 1 , the highest value of domain which has membership degree of 0 and the value of input which is about to be changed into fuzzy numbers.

\subsection{Fuzzy database}

Fuzzification of queries is assumed to be a conventional query (non fuzzy), a database management systems (DBMS) that tries to create and implement a basic logical system of fuzzy query (fuzzy logic based querying system). The advantage of query fuzzification is that it can achieve DBMS flexibility, automatic error handling, and flexible search. Fuzzy Tahani is one of the branches of fuzzy logic, which is one of the fuzzy methods that use a standard database. Tahani describes a query fuzzy processing method, which is based on the manipulation of a language known as SQL (structured query language), so fuzzy Tahani model is aptly used in precise and accurate data retrieval processes. Fuzzy database is used for reasoning using a database [4]. The overall process of block diagram can be seen in Figure 7. First, initialize device, and then measurement which is input and will be processed fuzzification. This research consists of hardware and software. Hardware is as instrumentation of laboratory measurement data while software is as storage and display of measurement DAS.

\subsection{Hardware design}

The block diagram design of the system in this study consists of server, client (Laptop, Desktop etc), Instrumentation and Module of Laboratory practice as shown in Figure 8. The diagram block of instrumentation consists of current and voltage sensors. The following is the circuit used as shown in Figures 9 and 10.

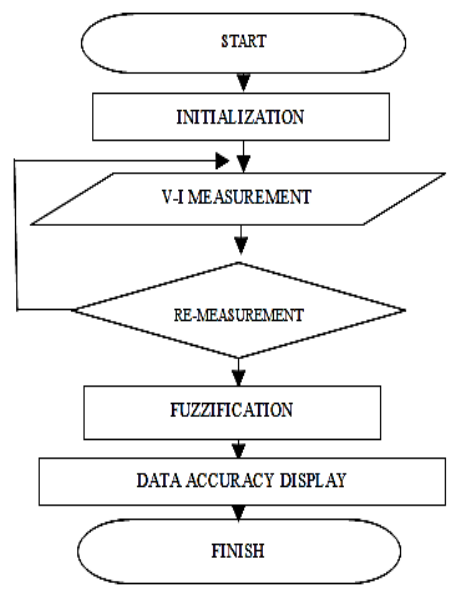

Figure 7. Research flow chart

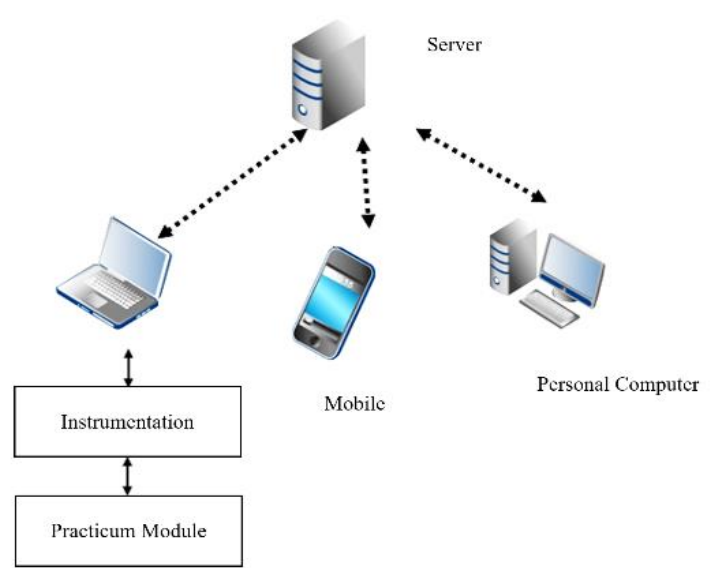

Figure 8 . Web based data acquisition system
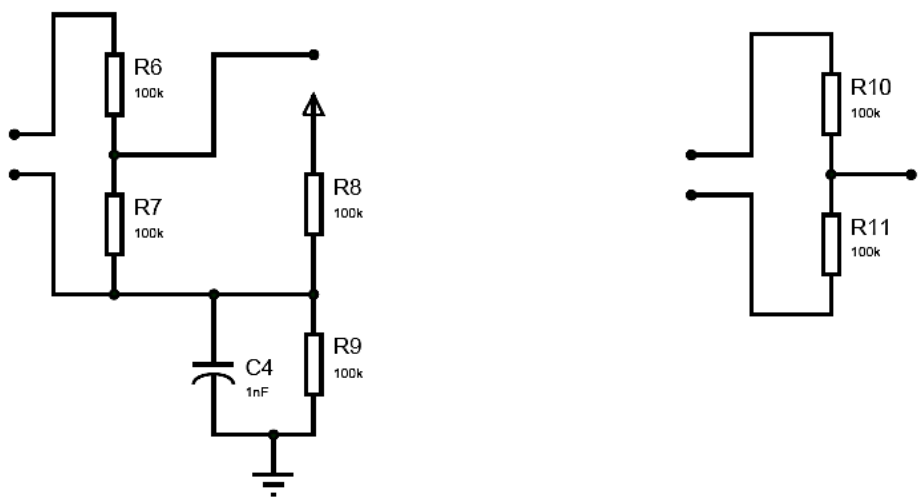

Figure 9. Set of voltage sensor 


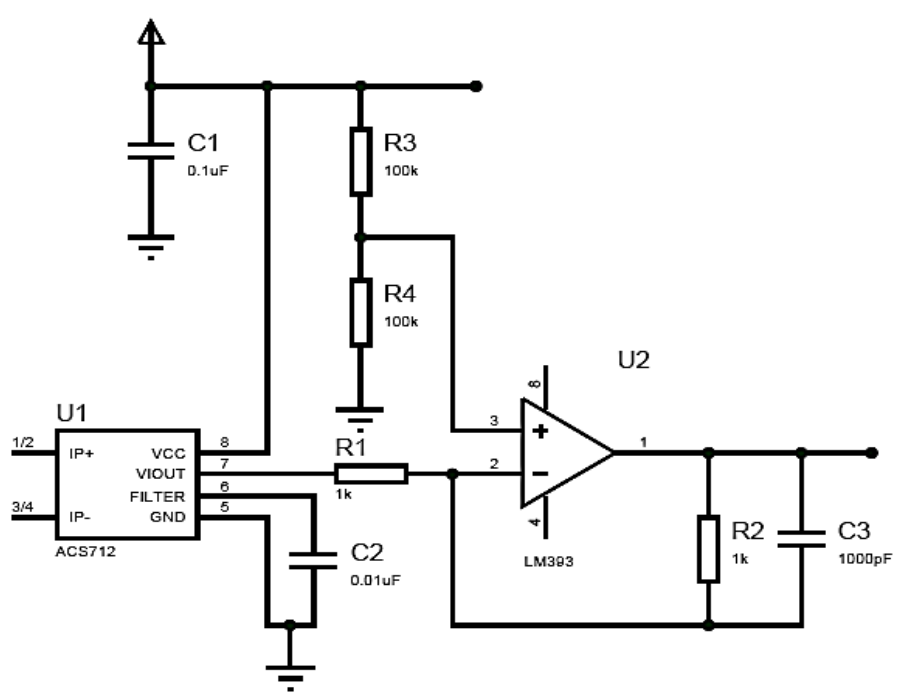

Figure 10. Set of current sensor

\subsection{Software design}

In making the website in this research, it would use Dreamweaver software and web server XAMPP 1.6.4 version by using programming language PHP and Mysql. In website view, there would be some menu like Practicum, Registration, Contact and Login. The use of this Web Server is used to analyze feedback $[27,28]$.

\section{RESULTS AND ANALYSIS}

The module of laboratory practice was determined as in Figure 11. The module in Figure 11 is a series of experiments carried out, namely set and parallel series for measurement module and electricity measuring instrument. After the experimental module was structured based on the above image, the acquisition instrumentation was connected with the laptop of practicing participants and then the measurement was conducted by opening the web browser as shown in Figure 12, and the result of voltage measurement as shown in Table 1 .

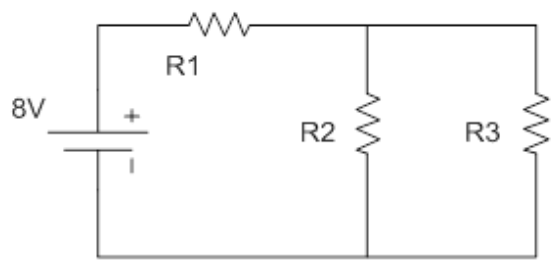

Figure 11. Research modul

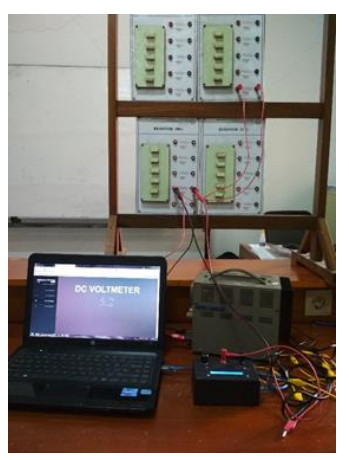

Figure 12. The experimental series of using data acquisition instrumentation 
Table 1. The Result of voltage measurement

\begin{tabular}{cccc}
\hline No. & Data & Measurement & Measurement (V) \\
\hline 1 & VR1 & First & 5,1 \\
2 & VR1 & Second & 5,3 \\
3 & VR1 & Third & 5,2 \\
4 & VR2 & First & 2,7 \\
5 & VR2 & Second & 2,6 \\
6 & VR2 & Third & 2,6 \\
\hline
\end{tabular}

With Resistor $\mathrm{R}=100 \Omega$ to find voltage values of VR1 and VR2, it should be based on calculation.

Known:

Series of Figure 9

R1,R2,R3=100 $\Omega$

Vin $=8 \mathrm{~V}$

Discussion:

$$
\begin{aligned}
& R_{\text {Parallel }}=\frac{R_{2} \times R_{3}}{R_{2}+R_{3}}=\frac{100 \times 100}{100+100}=50 \Omega \\
& V R_{1}=\frac{R_{1}}{R_{1}+R_{\text {Parallel }}} \times \text { Vin }=\frac{100 \Omega}{100 \Omega+50 \Omega} \times 8 \mathrm{~V}=5,3 \mathrm{~V} \\
& V R_{2}=\frac{R_{\text {parallel }}}{R_{1}+R_{\text {parallel }}} \times 8 \mathrm{~V}=\frac{50 \Omega}{100 \Omega+50 \Omega} \times 8 \mathrm{~V}=2,7 \mathrm{~V}
\end{aligned}
$$

At this stage, there is a fuzzification process i.e. the process of changing the membership data from the set of a weight of a regular score into the membership of the set of fuzzy numbers. The criteria used are shown in Figure 13.

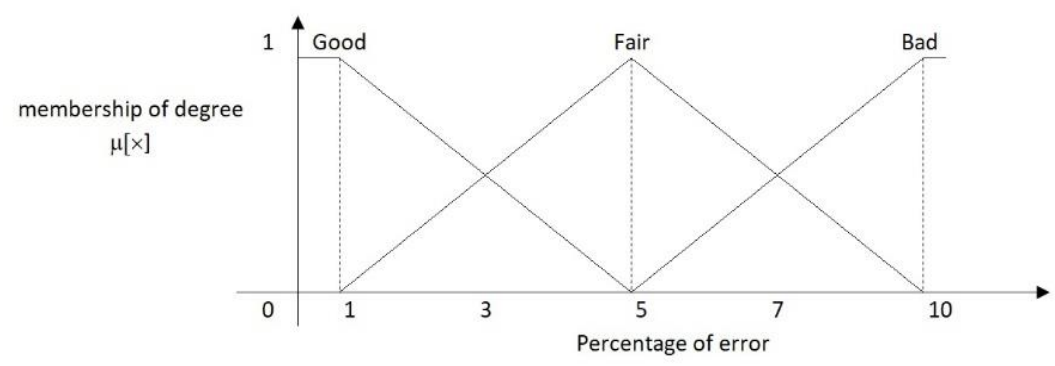

Figure 13. Membership of voltage measurement

$x 1=\left|\frac{\text { supposed voltage value }- \text { measured value }}{\text { measured value }}\right| x 100 \%$

$\mathrm{VR}_{1}$ measurement (first) $=5,1 \mathrm{~V}$

$x 1=\left|\frac{5,3-5,1}{5,1}\right| x 100 \%=3,39 \%$

$\mathrm{VR}_{1}$ measurement $($ second $)=5,3 \mathrm{~V}$

$x 1=\left|\frac{5,3-5,3}{5,3}\right| x 100 \%=0 \%$

$\mathrm{VR}_{1}$ measurement (third) $=5,2 \mathrm{~V}$ 
$x 1=\left|\frac{5,3-5,2}{5,2}\right| x 100 \%=1,92 \%$

$\mathrm{VR}_{2}$ measurement (first) $=2,7 \mathrm{~V}$

$x 1=\left|\frac{2,7-2,7}{2,7}\right| x 100 \%=0 \%$

$\mathrm{VR}_{2}$ measurement (second) $=2,6 \mathrm{~V}$

$x 1=\left|\frac{2,7-2,6}{2,6}\right| x 100 \%=3,85 \%$

$\mathrm{VR}_{2}$ measurement $($ third $)=2,6 \mathrm{~V}$

$x 1=\left|\frac{2,7-2,6}{2,6}\right| x 100 \%=3,85 \%$

From this percentage of error then, the degree of membership for each membership function was searched.

$$
\begin{gathered}
\mu \operatorname{Good}[x 1]=\left\{\begin{array}{cc}
1 ; & x 1 \leq 1 \\
(5-x 1) / 4 ; & 1 \leq x 1 \leq 5 \\
0 & x 1 \geq 5
\end{array}\right. \\
\mu \text { Fair }[x 1]=\left\{\begin{array}{cc}
0 ; & x 1 \leq \text { or } x 1 \geq 10 \\
(x 1-1) / 4 & 1 \leq x 1 \leq 5 \\
(10-x 1) / 5 ; & 5 \leq x 1 \leq 10
\end{array}\right. \\
\mu \operatorname{Bad}[x 1]=\left\{\begin{array}{cc}
0 ; & x 1 \leq 5 \\
(x 1-5) / 5 ; & 5 \leq x 1 \leq 10 \\
1 ; & x 1 \geq 10
\end{array}\right.
\end{gathered}
$$

Table 2 shows that the measurement result obtained from the experimental result was in the form of analogs which were converted to digital systems and processed via fuzzy with membership degree corresponding to the fuzzy calculations. Each measurement has a membership degree value of each on the membership of good, fair and bad shown in Figure 14. The result of Fuzzy processing as shown below is the result of Fuzzy Tahani processing, Table 2 is the result of VR1 and VR2 voltage measurement. The top recommendation is the measurement with the highest fire strength value indicating that the result of the measurement is closest to the desired criteria in the form of recommendation of laboratory practice measurement result used as experimental data.

The result of the recommendation shown in Figure 15 is the output of the fuzzy process, using Tahani's fuzzy method to determine the recommendation of the measurement value of the practicum used i.e. taking the query that has the maximum value of the membership degree data of each fuzzy membership existed in the data base in Table 2. Web display in this study has been responsive and flexible which means that web display which will adjust to the size of viewport (the extent of area in browser to display website) used by users when accessing a website whenever the users use laptop, tab, or smartphone, so that it is very

\begin{tabular}{|c|c|c|c|c|c|c|}
\hline \multirow[t]{2}{*}{ No } & \multirow[t]{2}{*}{ Data } & \multirow[t]{2}{*}{ Measurement (V) } & \multirow[t]{2}{*}{$\%$ Error } & \multicolumn{3}{|c|}{ Membership Degree } \\
\hline & & & & Good & Fair & Bad \\
\hline 1 & $\mathrm{VR}_{1}(1)$ & 5,1 & 3,92 & 0,27 & 0,73 & 0,00 \\
\hline 2 & $\mathrm{VR}_{1}(2)$ & 5,3 & 0,00 & 1,00 & 0,00 & 0,00 \\
\hline 4 & $\mathrm{VR}_{2}(1)$ & 2,7 & 0,00 & 1,00 & 0,00 & 0,00 \\
\hline 5 & $\mathrm{VR}_{2}(2)$ & 2,6 & 3,85 & 0,29 & 0,71 & 0,00 \\
\hline 6 & $\mathrm{VR}_{2}(3)$ & 2,6 & 3,85 & 0,29 & 0,71 & 0,00 \\
\hline
\end{tabular}
easy to use.

Table 2. Voltage measurement and fuzzy membership degree 


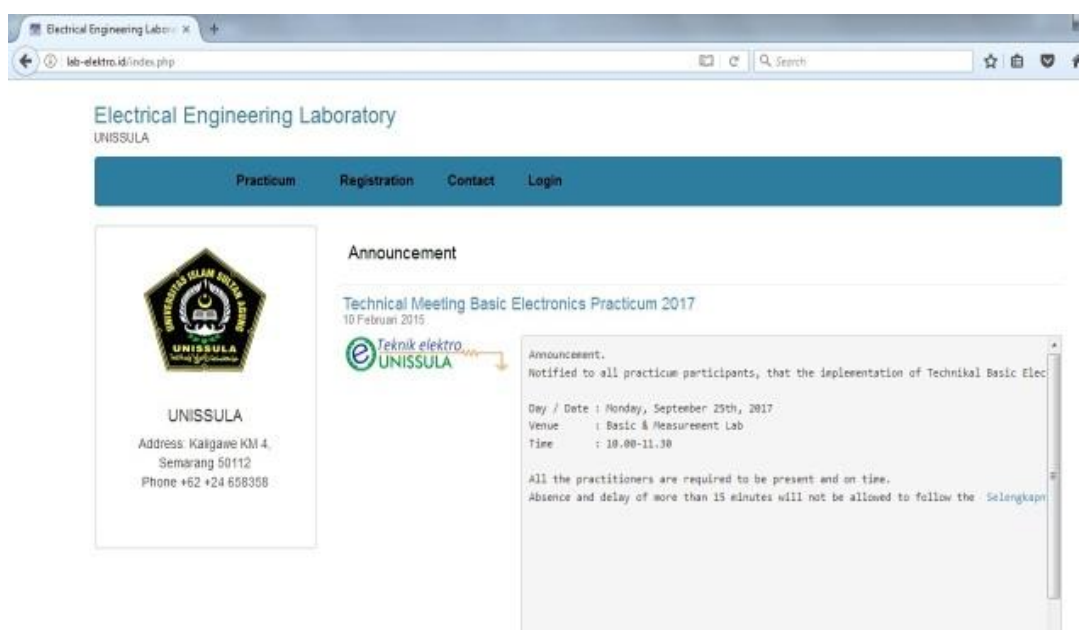

Figure 14. Web main display of electrical engineering lab

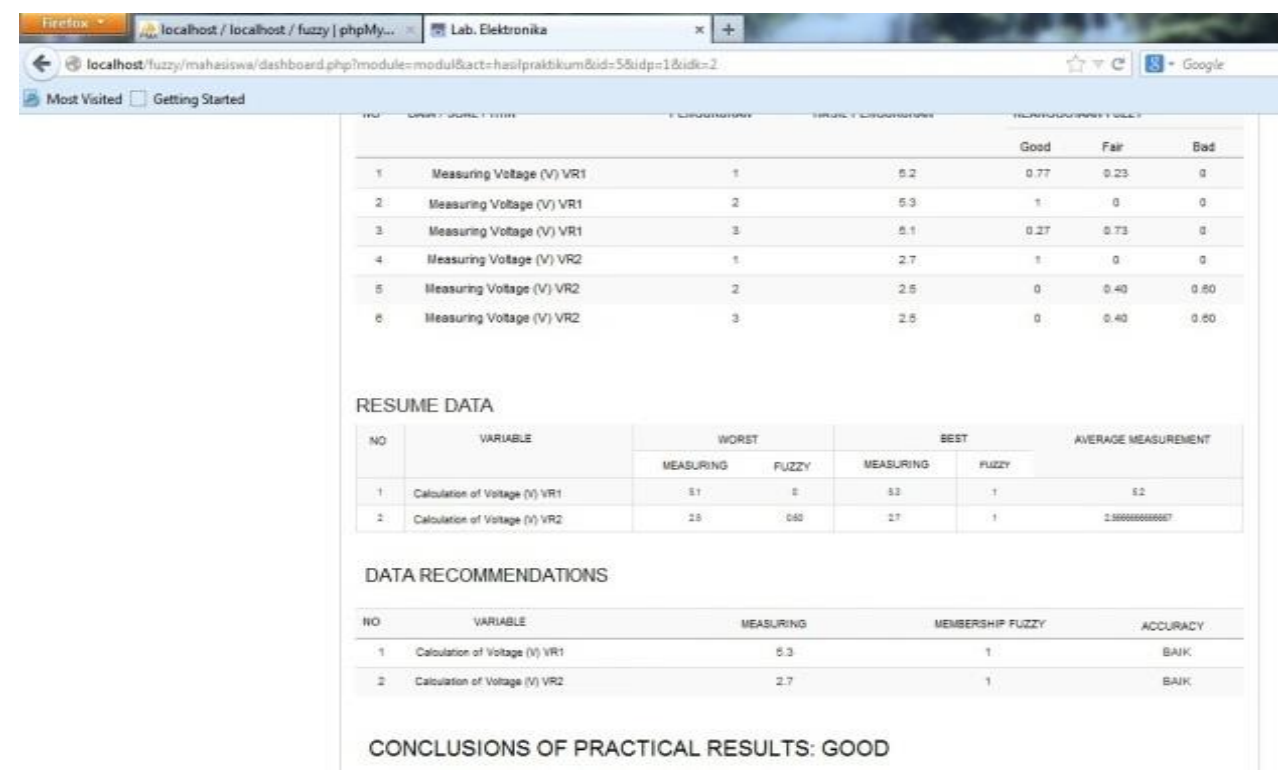

Figure 15. Web display of measurement recommendation result

\section{CONCLUSION}

DAS can be implemented in the measurement of current and voltage in laboratory works. Fuzzy logic method is able to analyze criteria and then give the order of measurement priority with the value of fire strength between $0-1$. The ultimate result of this study has been successful in making system which can help the Laboratory practice participants in laboratory to save measurement data digitally with no paper (paperless), where the data are saved on web server database.

\section{REFERENCES}

[1] A. Peña-Ríos, V. Callaghan, M. Gardner, and M. J. Alhaddad, "Remote mixed reality collaborative laboratory activities: Learning activities within the InterReality Portal," in Proceedings of the The 2012 IEEE/WIC/ACM International Joint Conferences on Web Intelligence and Intelligent Agent Technology, vol. 03, pp. 362-366, 2012.

[2] J. Marquez, J. Villanueva, Z. Solarte, and A. Garcia, "IoT in education: Integration of objects with virtual academic communities," in New Advances in Information Systems and Technologies, Springer, pp. 201-212, 2016.

[3] H. Aldowah, S. U. Rehman, S. Ghazal, and I. N. Umar, "Internet of Things in higher education: a study on future learning," in Journal of Physics: Conference Series, vol. 892, 012017, 2017.

[4] Z. Tianbo, "The internet of things promoting higher education revolution," in 2012 Fourth International Conference on Multimedia Information Networking and Security, pp. 790-793, 2012. 
[5] G. C. Fernandez, E. S. Ruiz, M. C. Gil, and F. M. Perez, "From RGB led laboratory to servomotor control with websockets and IoT as educational tool," in Proceedings of 2015 12th International Conference on Remote Engineering and Virtual Instrumentation (REV), pp. 32-36, 2015.

[6] P. Arpaia, A. Baccigalupi, F. Cennamo, and P. Daponte, "A measurement laboratory on geographic network for remote test experiments," IEEE Trans. Instrum. Meas., vol. 49, no. 5, pp. 992-997, 2000.

[7] I. Gustavsson, "Remote laboratory experiments in electrical engineering education," in Proceedings of the fourth IEEE international caracas conference on devices, circuits and systems (Cat. No. 02TH8611), pp. I025-I025, 2002.

[8] J. Broisin, R. Venant, and P. Vidal, "Lab4CE: a remote laboratory for computer education," Int. J. Artif. Intell. Educ., vol. 27, no. 1, pp. 154-180, 2017.

[9] H. Zhiqiang and Z. Junming, "The Application of Internet of Things in Education and Its Trend of Development," J. Mod. Distance Educ. Res., vol. 2, no. 19, 2011.

[10] N. Dlodlo and A. C. Smith, "Internet-of-things in remote-controlled laboratories," Conference: Proceedings of the 13th Annual Conference on World wide Web Applications ZA WWW 2013, At Johannesburg, South Africa, 2011.

[11] J. He, D. C.-T. Lo, Y. Xie, and J. Lartigue, "Integrating Internet of Things (IoT) into STEM undergraduate education: Case study of a modern technology infused courseware for embedded system course," in 2016 IEEE Frontiers in Education Conference (FIE), pp. 1-9, 2016.

[12] M. A. Sanchez, J. R. Castro, O. Castillo, O. Mendoza, A. Rodriguez-Diaz, and P. Melin, "Fuzzy higher type information granules from an uncertainty measurement," Granul. Comput., vol. 2, no. 2, pp. 95-103, 2017.

[13] G. Huang and L. Zhao, "Measurement based voltage stability monitoring of power system," Power Syst. Eng. Res. Center, 2001.

[14] Z. Li, H. Li, Z. Zhang, and P. Luo, "An Online Calibration Method for Electronic Voltage Transformers Based on IEC 61850-9-2,” Mapan - J. Metrol. Soc. India, vol. 29, no. 2, pp. 97-105, 2014.

[15] R. S. Bhadoria, N. S. Chaudhari, and S. Samanta, "Uncertainty in sensor data acquisition for SOA system," Neural Computing and Applications, pp. 1-11, 2017.

[16] O. Sarchami and H. Bevrani, "Online Voltage-Frequency Measurement Based Micro-Grid Emergency Control," in Conference of Technology, Energy, and Data on Electrical and Computer Engineering, Kermanshah, Iran 2015.

[17] M. M. Baig, H. GholamHosseini, A. Kouzani, and M. J. Harrison, "Anaesthesia monitoring using fuzzy logic," J. Clin. Monit. Comput., vol. 25, no. 5, pp. 339-347, 2011.

[18] West Har, "Decision Support Systems," Inf. Manag., vol. 5, no. 3, pp. 187-191, 1982.

[19] S. Ramamoorthy, "Design and implementation of fuzzy logic based power system stabilizers," Middle-East J. Sci. Res., vol. 20, no. 11, pp. 1663-1666, 2014.

[20] Raghavendra P and D. N. Gaonkar, "Online voltage estimation and control for smart distribution networks," J. Mod. Power Syst. Clean Energy, vol. 4, no. 1, pp. 40-46, 2016.

[21] Austerlich H., "Data Acquitition Technique Using PC," Orlando: Academic Press, 2003.

[22] A.R. Hasan, T.S. Martis, and A.H.M. Sadrul Ula, "Design and implementation of a fuzzy controller based automatic voltage regulator for a synchronous generator," Energy Conversion, IEEE Trans., vol. 9, no. 3, pp. 550-557, 1994.

[23] B. J. Lameres, "Design and Implementation of a Fuzzy Logic-Based Voltage Controller for Voltage Regulation of a Synchronous Generator," Montana State University, pp. 1-8.

[24] L. a. Zadeh, "Fuzzy sets," Inf. Control, vol. 8, no. 3, pp. 338-353, 1965.

[25] B. Belhadj and M. S. Matoussi, "Poverty in Tunisia: A Fuzzy Measurement Approach," Swiss J. Econ. Stat., vol. 146, no. II, pp. 431-450, 2010.

[26] W. Hartford, "Decision Support Systems," Inf. Manag., vol. 5, no. 3, pp. 187-191, 1982.

[27] M. Loudini, S. Rezig, and Y. Salhi, "Incorporate intelligence into the differentiated services strategies of a web server: An advanced feedback control approach," J. Internet Serv. Appl., vol. 4, no. 1, pp. 1-16, 2013.

[28] M. J. Karki, "Methods for online voltage stability monitoring," Iowa State University, 2009. 